University of Massachusetts Amherst

ScholarWorks@UMass Amherst

Chemistry Department Faculty Publication Series

Chemistry

1996

\title{
Use of surfactant in the determination of arsenic by flow injection hydride generation atomic absorption spectrometry
}

Julian Tyson

University of Massachusetts Amherst

Robert Ellis

University of Massachusetts Amherst

Follow this and additional works at: https://scholarworks.umass.edu/chem_faculty_pubs

Part of the Chemistry Commons

\section{Recommended Citation}

Tyson, Julian and Ellis, Robert, "Use of surfactant in the determination of arsenic by flow injection hydride generation atomic absorption spectrometry" (1996). Spectrochimica Acta Part B. 1318.

Retrieved from https://scholarworks.umass.edu/chem_faculty_pubs/1318 


\title{
Use of a surfactant in the determination of arsenic by flow injection hydride generation atomic absorption spectrometry ${ }^{1}$
}

\author{
Robert I. Ellis, Julian F. Tyson* \\ Department of Chemistry, Box 34510, University of Massachusetts, Amherst, MA 01003-4150, USA
}

Received 10 April 1996; accepted 19 June 1996

\begin{abstract}
The possible benefits of the addition of an anionic surfactant, didodecyldimethylammonium bromide, in the determination of arsenic, by flow injection hydride generation atomic absorption spectrometry using a flame-heated quartz tube atomizer, were studied in the light of previous reports concerning the effects of surfactants on chemical vapor generation procedures. Concentrations of arsenic between 5 and $30 \mu \mathrm{g} \mathrm{l}^{-1}$ were used. Calibrations in the presence and absence of the surfactant in the sample solution were not significantly different, either for the case where vesicles were formed in the presence of the analyte or where they were preformed in the surfactant solution and then added to the analyte. The surfactant had no effect on recoveries in the presence of copper, nickel or bismuth. The addition of the surfactant to the acid carrier and/or borohydride streams had no effect. It is proposed that there may be a greater role for surfactants in the improvement of the processes by which the hydride is transferred to the bulk gas phase than has been attributed in previous reports on this subject.
\end{abstract}

Keywords: As; Flow injection; Hydride generation AAS; Quartz tube; Surfactant

\section{Introduction}

It has been claimed in recent reports [1-7] that in the determination of hydride forming elements by atomic spectrometry, an improvement in sensitivity may be achieved by the addition of surfactants. Several of these studies also report an increased tolerance to potential interferences in the presence of the surfactants and in some cases the presence of the surfactant is said to be "essential for the efficient formation of the volatile species in the reaction vessel" [6]. These phenomena have been investigated for several elements including arsenic [3], lead [1,2],

\footnotetext{
* Corresponding author.

${ }^{1}$ This paper was published in the Special Issue of Spectrochima Acta, Part B, devoted to Flow Analysis.
}

and cadmium [4-6]. A similar effect has been reported in the determination of mercury by "cold vapor" procedures [7-10]. Detection techniques have included both inductively coupled plasma atomic emission spectrometry (ICP-AES) and atomic absorption spectrometry (AAS). Surfactants are known to create a micro-environment of organized molecular assemblies which may change reaction rates, chemical equilibria and selectivity in reactions within the media [11]. Further, it has been proposed that in addition to kinetic and thermodynamic advantages, surfactants may help to stabilize a given oxidation state of the analyte, and to inhibit the solubility of volatile species in the organized media, thus favoring the bulk solvent and hence improving transport to the atomizer [7]. There have been numerous publications regarding the use of surfactants in flame AAS 
concerned with possible increases in nebulizer efficiency. This use of surfactants, however, has not been without its criticisms [12].

A wide range of surfactants are available, each displaying its own characteristics in the formation of a micro-environment. Classifications of surfactants include those capable of forming cationic, anionic, non-ionic and zwitterionic micelles, and cationic and anionic vesicles [11]. Micelles are colloidal sized assemblies formed by individual monomers with hydrophobic and hydrophilic end groups in dilute solutions. In these assemblies, the hydrophobic and hydrophilic end groups aggregate form an essentially spherical assembly, in which the hydrophobic regions of each monomer are positioned within the sphere and the hydrophilic groups form the surface of the sphere. Therefore, a hydrophobic region is enclosed within a hydrophilic shell. Vesicles are closed bi-layer structures which may be formed by double chain surfactants and lipids with adequate aggregation. In these assemblies a bi-layer is formed by the aggregation of hydrophobic and hydrophilic end groups of monomers into a sandwich membrane structure with a hydrophobic center and hydrophilic outer surfaces. These can form spherical structures in which a hydrophilic center is surrounded by a bi-layered wall with a hydrophobic center. For those surfactants which form micelles, a concentration exists at which micelle formation is spontaneous, i.e. the critical micelle concentration (CMC). Vesicles are commonly formed by either ultrasonic dispersion of the surfactant in aqueous solution at a temperature above the phase transition temperature of the vesicle, or by gentle injection of a non-aqueous dialkyl surfactant into aqueous solution. Vesicles are less dynamic than micelles but are significantly more stable.

The use of hydride generation for the determination of arsenic is an established procedure with a substantial literature [13], from which it is clear that there is a continuing drive towards the development of methods with ever-decreasing detection capability and freedom from interferences. It is also apparent that the chemistry involved is of considerable complexity as there are inconsistencies in the reported results, indicating that there are factors involved which are not yet fully under control. As there is considerable interest in the development of flow injection (FI) procedures for the implementation of chemical vapor generation methodology [14], the possible benefits of the use of a surfactant, didodecyldimethylammonium bromide (DDAB), in the determination of arsenic are reported here. Previous work [3] showed DDAB to give improved performance (sensitivity enhancement, decreased detection limit and greater tolerance to interferences) in both continuous flow and batch procedures for the determination of this element. In our study, the proposed increase in sensitivity and selectivity has been investigated using aqueous solutions of As(III) determined by FI hydride generation AAS with a flame-heated quartz tube atomizer.

\section{Experimental}

\subsection{Instrumentation}

A Perkin-Elmer 3100 atomic absorption spectrometer was coupled with the hydride generation

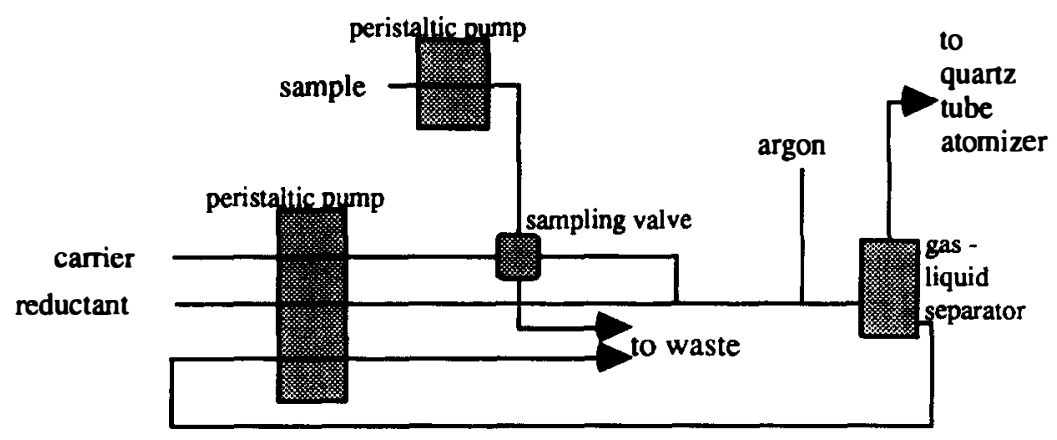

Fig. 1. Flow injection manifold. 
manifold as shown in Fig. 1. The instrument was interfaced with a Digital 316sx workstation and controlled using Perkin-Elmer Gem software. A single element arsenic hollow cathode lamp was installed in the instrument and operated at $15 \mathrm{~mA}$ throughout. A wavelength of $193.7 \mathrm{~nm}$ was selected with a bandpass of $0.7 \mathrm{~nm}$. A Perkin-Elmer quartz tube atomizer was positioned in an air/acetylene flame and connected directly to the gas port on a Perkin-Elmer glass gasliquid separator, shown in Fig. 2. Peak height data were collected by the software and smoothed using a 37 point moving average smoothing function. Each determination was performed in quadruplicate. The quartz cell was periodically reconditioned as follows. The cell was soaked in a warm solution of laboratory detergent diluted 1:4 with tap water. The cell was then rinsed successively with warm tap water, $20 \%$ hydrochloric acid solution, tap water, deionized distilled water and acetone.

The FI manifold was constructed using Ismatec reglo-Ms variable speed peristaltic pumps coupled with teflon manifold tubing $(0.508 \mathrm{~mm}$ internal diameter) and Perkin-Elmer chemifold blocks. The flow rate of the carrier stream was set at $4 \mathrm{ml} \mathrm{min}^{-1}$ and that of the reductant stream at $2.5 \mathrm{ml} \mathrm{min}{ }^{-1}$. The sample loop volume was $500 \mu \mathrm{l}$ and the argon flow rate was $36 \mathrm{ml} \mathrm{min}^{-1}$. Samples were injected using a manually operated six-port valve. A high intensity ultrasonic probe (Sonics and Materials model VS50 S) was used for the dispersion of the surfactant in the solutions.

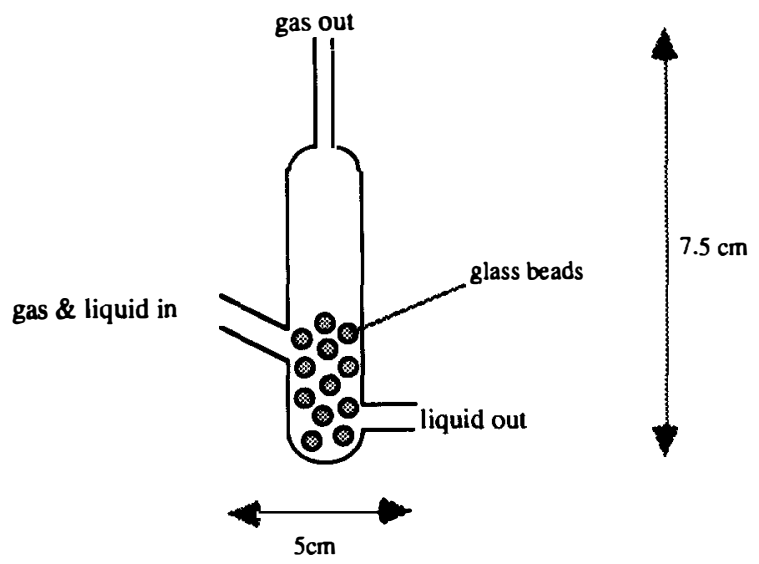

Fig. 2. Gas-liquid separator.

\subsection{Reagents and solutions}

The carrier stream was $10 \% \mathrm{v} / \mathrm{v}$ hydrochloric acid (Fisher) in purified water. The reductant stream was $0.4 \% \mathrm{~m} / \mathrm{v}$ sodium borohydride (Fisher) and $0.05 \% \mathrm{w} / \mathrm{v}$ sodium hydroxide in purified water. A $10 \% \mathrm{~m} / \mathrm{v}$ ascorbic acid (Fisher) solution and a $10 \% \mathrm{~m} / \mathrm{v}$ potassium iodide (Fisher) solution were prepared by dissolving the solids in purified water. A $500 \mu \mathrm{g} \mathrm{l}^{-1}$ arsenic(V) solution was prepared by diluting certified atomic absorption standard (Perkin-Elmer) with purified water. A $10^{-2} \mathrm{M}$ DDAB (Kodak) solution was prepared by adding the solid to purified water and treating with the tip of the ultrasonic probe for $12 \mathrm{~min}$.

Solutions without DDAB were prepared as follows. To a $100 \mathrm{ml}$ calibrated flask, $10 \mathrm{ml}$ ascorbic acid solution $(10 \% \mathrm{~m} / \mathrm{v}), 10 \mathrm{ml}$ potassium iodide solution $(10 \% \mathrm{~m} / \mathrm{v}), 10 \mathrm{ml}$ concentrated hydrochloric acid (to give a final concentration of $10 \% \mathrm{v} / \mathrm{v}$ ) and an aliquot of $500 \mu \mathrm{g} \mathrm{l}^{-1} \mathrm{As}(\mathrm{V})$ solution as necessary were added. This mixture was stoppered and left at room temperature for $1 \mathrm{~h}$ to ensure reduction of $\mathrm{As}(\mathrm{V})$ to $\mathrm{As}(\mathrm{III})$ prior to dilution to volume with purified water.

Solutions with pre-dispersed DDAB were prepared as follows. To a $100 \mathrm{ml}$ calibrated flask, $10 \mathrm{ml}$ ascorbic acid solution $(10 \% \mathrm{~m} / \mathrm{v}), 10 \mathrm{ml}$ potassium iodide solution $(10 \% \mathrm{w} / \mathrm{v}), 10 \mathrm{ml}$ hydrochloric acid $(10 \% \mathrm{v} / \mathrm{v}), 10 \mathrm{ml}$ DDAB solution $\left(10^{-2} \mathrm{M}\right)$ and an aliquot of $500 \mu \mathrm{g} \mathrm{l}^{-1} \mathrm{As}(\mathrm{V})$ solution as necessary were added. This mixture was stoppered and left at room temperature for $1 \mathrm{~h}$ to ensure reduction of $\mathrm{As}(\mathrm{V})$ to As(III) prior to dilution to volume with purified water.

Solutions with post-dispersed DDAB were prepared as follows. To a $100 \mathrm{ml}$ calibrated flask, 10 $\mathrm{ml}$ ascorbic acid solution $(10 \% \mathrm{~m} / \mathrm{v}), 10 \mathrm{ml}$ potassium iodide solution $(10 \% \mathrm{~m} / \mathrm{v}), 10 \mathrm{ml}$ hydrochloric acid $(10 \% \mathrm{v} / \mathrm{v})$, sufficient solid DDAB to form a final concentration of $10^{-3} \mathrm{M}$ and an aliquot of $500 \mu \mathrm{g} \mathrm{l}^{-1}$ As(V) solution as necessary were added. This mixture was stoppered and left at room temperature for $1 \mathrm{~h}$ to ensure reduction of $\mathrm{As}(\mathrm{V})$ to $\mathrm{As}(\mathrm{III})$ prior to dilution to volume with purified water. The solution was then treated with the tip of a high intensity ultrasonic probe for 12 min to disperse the DDAB.

A carrier stream containing DDAB was prepared by including $10 \% \mathrm{v} / \mathrm{v}$ DDAB solution $\left(10^{-2} \mathrm{M}\right)$ in a 
Table 1

Mean absorbance values and standard deviations $(n=4)$ for samples with and without DDAB

\begin{tabular}{|c|c|c|c|c|c|}
\hline & Blank & $5 \mu \mathrm{g} \mathrm{I}^{-1}$ As & $10 \mu \mathrm{g} \mathrm{I}^{-1}$ As & $15 \mu \mathrm{g} \mathrm{I}^{-1} \mathrm{As}$ & $20 \mu \mathrm{gl}^{-1} \mathrm{As}$ \\
\hline \multicolumn{6}{|c|}{ Samples without $D D A B$} \\
\hline Mean & 0.052 & 0.124 & 0.210 & 0.270 & 0.316 \\
\hline Std. dev. & 0.006 & 0.001 & 0.004 & 0.007 & 0.012 \\
\hline \multicolumn{6}{|c|}{ Samples with pre-dispersed $D D A B$} \\
\hline Mean & 0.062 & 0.136 & 0.212 & 0.265 & 0.327 \\
\hline Std. dev. & 0.003 & 0.005 & 0.014 & 0.015 & 0.012 \\
\hline \multicolumn{6}{|c|}{ Samples with post-dispersed $D D A B$} \\
\hline Mean & 0.068 & 0.143 & 0.222 & 0.266 & 0.322 \\
\hline Std. dev. & 0.005 & 0.008 & 0.011 & 0.012 & 0.007 \\
\hline
\end{tabular}

carrier stream otherwise made as detailed above. A reductant stream containing DDAB was prepared by including $10 \%$ DDAB v/v $\left(10^{-2} \mathrm{M}\right)$ in a reductant stream otherwise made as detailed above. To inhibit foaming during analysis using these solutions, $1 \% \mathrm{v} / \mathrm{v}$ silicon anti-foaming agent (Dow Corning 110A supplied by Perkin-Elmer) was included in each sample when analyzed using these reagents.

To investigate the effect of DDAB on the signal in the presence of elements known to cause interference, the following solutions were prepared. To three calibrated flasks was added $25 \mathrm{ml}$ of As standard without DDAB followed by $20 \mathrm{ml}$ of $\mathrm{Cu}$ atomic absorption standard (1000 mg l$~^{-1}$ Perkin-Elmer), $20 \mathrm{ml}$ of Ni atomic absorption standard $\left(1000 \mathrm{mg} \mathrm{l}^{-1}\right.$ PerkinElmer) or $20 \mathrm{ml}$ purified water. The same solutions were also prepared with $25 \mathrm{ml}$ aliquots of the As solution containing DDAB. To a calibrated flask, 50 $\mathrm{ml}$ As standard solution without DDAB followed by 1 $\mathrm{ml}$ bismuth atomic standard solution $\left(1000 \mathrm{mg} \mathrm{l}^{-1}\right.$ Perkin-Elmer) were added. A second solution was made which included DDAB.

\section{Results and discussion}

\subsection{Comparison of sensitivity obtained from solutions with and without $D D A B$}

Three sets of solutions of As(III) were analyzed. The first set contained no DDAB. The second set of solutions contained DDAB solution, pre-dispersed using an ultrasonic probe, and was labeled "pre-dispersed". The third set, to which solid DDAB had been added before treatment with an ultrasonic probe, were labeled "post-dispersed". The solutions were analyzed using the procedure described in the previous section. The mean and standard deviation of the four replicate measurements for each solution are tabulated in Table 1. One-way analysis of variance (ANOVA) tests were applied to the results for the samples with and without DDAB at each concentration. The difference between the results from the blank samples was highly significant at the $95 \%$ confidence interval, and also significant for the $5 \mu \mathrm{g} \mathrm{l}^{-1}$ samples if not blank corrected. Linear regression has

Table 2

Linear regression values for data from Table 1 including $95 \%$ confidence interval

\begin{tabular}{llll}
\hline Sample & Intercept & Slope & $R^{2}$ \\
\hline Without DDAB & $0.060 \pm 0.031$ & $0.013 \pm 0.003$ & 0.988 \\
With pre-dispersed DDAB & $0.069 \pm 0.017$ & $0.013 \pm 0.003$ & 0.995 \\
With post-dispersed DDAB & $0.078 \pm 0.027$ & $0.013 \pm 0.003$ & 0.988 \\
\hline
\end{tabular}


Table 3

Mean absorbance values and standard deviations $(n=4)$ for samples with and without DDAB, using carrier and reductant streams with and without DDAB

\begin{tabular}{|c|c|c|c|c|c|}
\hline $\begin{array}{l}\text { DDAB in } \\
\text { carrier stream }\end{array}$ & $\begin{array}{l}\text { DDAB in } \\
\text { reagent stream }\end{array}$ & $\begin{array}{l}5 \mu \mathrm{g} \mathrm{l}^{-1} \text { As } \\
\text { w/out DDAB }\end{array}$ & $\begin{array}{l}10 \mu \mathrm{g} \mathrm{l}^{-1} \mathrm{As} \\
\text { w/out DDAB }\end{array}$ & $\begin{array}{l}5 \mu \mathrm{g} \mathrm{l}^{-1} \mathrm{As} \\
\text { with DDAB }\end{array}$ & $\begin{array}{l}10 \mu \mathrm{g} \mathrm{l}^{-1} \mathrm{As} \\
\text { with DDAB }\end{array}$ \\
\hline & & \multicolumn{4}{|c|}{ Mean absorbances } \\
\hline No & No & 0.237 & 0.388 & 0.226 & 0.363 \\
\hline No & Yes & 0.240 & 0.382 & 0.237 & 0.373 \\
\hline Yes & No & 0.240 & 0.396 & 0.247 & 0.366 \\
\hline \multirow[t]{2}{*}{ Yes } & Yes & 0.243 & 0.382 & 0.244 & 0.366 \\
\hline & & \multicolumn{4}{|c|}{ Standard deviations } \\
\hline No & No & 0.004 & 0.019 & 0.003 & 0.005 \\
\hline No & Yes & 0.004 & 0.010 & 0.007 & 0.010 \\
\hline Yes & No & 0.005 & 0.004 & 0.002 & 0.011 \\
\hline Yes & Yes & 0.017 & 0.009 & 0.012 & 0.004 \\
\hline
\end{tabular}

been carried out on these data, the results of which are shown in Table 2. The confidence intervals of the intercepts overlap considerably; hence, it is clear that a significant improvement in detection limit cannot be claimed. The slopes of each curve are the same, so an improvement in sensitivity was not observed. Therefore, it may not be inferred that the addition of DDAB resulted in a significant increase in either sensitivity or detection limit for samples containing As(III).

\subsection{Addition of DDAB to carrier and reductant streams}

In order to attain the maximum presence of surfactant, DDAB was added to all components of the FI hydride generation procedure. A series of solutions of As(III) was prepared with and without DDAB. Carrier stream and reductant streams were also prepared with and without DDAB. All combinations were used in the analysis of the solutions, the results of which are shown in Table 3. Once again, the mean and standard deviations of the four replicate measurements are tabulated. A one-way ANOVA was carried out for mean absorbances for all samples of each concentration. At $5 \mu \mathrm{g} \mathrm{l}^{-1}$ there was no significant difference between the mean absorbances for any sample at the 95\% confidence interval. A significant difference between samples with and without DDAB was observed for the $10 \mu \mathrm{g} \mathrm{l}^{-1}$ sample, but this is attributed to a higher signal from those samples which did not contain DDAB. ANOVA tests for the four types of measurement for samples either with or without DDAB revealed no significant differences. Therefore, there is no evidence of a difference between absorbance values from samples in which DDAB was included in the carrier and/or reductant stream. However, it may be noted that those $10 \mu \mathrm{g} \mathrm{l}^{-1}$ As(III) samples not containing DDAB gave higher absorbances than those that did contain DDAB. Excessive foaming in the gas-liquid separator was considered to be a problem in this investigation. Foaming causes moisture to rise through the gas transfer line to the quartz tube atomizer, resulting in degradation of the tube and fogging of the windows. However, this was reduced by the inclusion of $1 \% \mathrm{v} / \mathrm{v}$ silicon antifoaming agent.

\subsection{Selectivity studies}

Aizpún Fernández et al. [3] observed an increase in signal for solutions containing DDAB in the presence of elements which normally suppress the arsenic AAS signal following hydride generation. Solutions of As(III) with and without DDAB were loaded with high concentrations of copper (444 $\left.\mathrm{mg} \mathrm{l}^{-1}\right)$, nickel (444 $\mathrm{mg} \mathrm{l}^{-1}$ ) and bismuth (20 $\left.\mathrm{mg} \mathrm{l}^{-1}\right)$, which may cause signal suppression in this determination. These were compared with solutions in which an interfering element was not present. The results for copper are shown in Table 4 and Table 5 . The percentage recovery figures represent the difference between each solution and that containing no DDAB and no interferent, and illustrate the reduction in recovery 
Table 4

Mean absorbance values and standard deviations $(n=4)$ for samples with and without DDAB, and with and without copper

\begin{tabular}{|c|c|c|c|c|}
\hline & Blank & $6 \mu \mathrm{g} \mathrm{l}^{-1}$ & $11 \mu \mathrm{g} \mathrm{l}^{-1} \mathrm{As}$ & $28 \mu \mathrm{g} \mathrm{l}^{-1} \mathrm{As}$ \\
\hline \multicolumn{5}{|c|}{ Without $D D A B$, no interferent } \\
\hline Mean & 0.030 & 0.094 & 0.133 & 0.245 \\
\hline Std. dev. & 0.008 & 0.016 & 0.010 & 0.003 \\
\hline \multicolumn{5}{|c|}{ With $D D A B$, no interferent } \\
\hline Mean & 0.030 & 0.099 & 0.142 & 0.252 \\
\hline Std. dev. & 0.004 & 0.004 & 0.009 & 0.005 \\
\hline \multicolumn{5}{|c|}{ Without DDAB, $444 \mathrm{mg} \mathrm{l}^{-1}$ copper interferent } \\
\hline Mean & 0.025 & 0.068 & 0.103 & 0.189 \\
\hline Std. dev. & 0.007 & 0.004 & 0.013 & 0.006 \\
\hline$\%$ recovery & 83 & 72 & 77 & 77 \\
\hline \multicolumn{5}{|c|}{ With $D D A B, 444 \mathrm{mgl}^{-1}$ copper interferent } \\
\hline Mean & 0.029 & 0.066 & 0.100 & 0.189 \\
\hline Std. dev. & 0.006 & 0.007 & 0.002 & 0.008 \\
\hline$\%$ recovery & 97 & 70 & 75 & 77 \\
\hline
\end{tabular}

observed. The presence of nickel did not significantly suppress the recovery, although there was no difference in recovery from solutions with and without DDAB. Significant recovery suppression was observed in the presence of bismuth, but once again there was no difference between recovery from those solutions containing DDAB and those without. It can be seen that the presence of DDAB did not affect the signal obtained in the presence of the interferent.

\subsection{Sensitivity variations}

It is clear that during the course of these studies (a period of several weeks), considerable variations in sensitivity were obtained. As can be seen from Tables 1,3 and 4 , the absorbance for a $10 \mu \mathrm{g} \mathrm{l}^{-1}$ As solution varied between 0.1 and 0.3 . Such sensitivity variations are a common feature of hydride generation procedures which use a flame-heated quartz cell atomizer, and provide one reason why it is difficult to optimize such procedures using rigorous optimization strategies that may require several days (or weeks) of experimental work. In our study, the quartz cell was reconditioned on several occasions using the procedure described earlier (which represents yet another use of surfactants in chemical vapor generation procedures). It is possible that enhanced hydride generation kinetics caused by the presence of the surfactant were offset by changes in sensitivity due to changes in the nature of the interior surface of the quartz tube.

\section{Conclusions}

It is clear that the role of surfactants in the hydride generation process is not yet unambiguously

Table 5

Linear regression values for the data in Table 4 including the $95 \%$ confidence interval

\begin{tabular}{llll}
\hline Sample & Intercept & Slope & $R^{2}$ \\
\hline Without DDAB, no interferent & $0.042 \pm 0.029$ & $0.007 \pm 0.003$ & 0.987 \\
With DDAB, no interferent & $0.045 \pm 0.038$ & $0.008 \pm 0.003$ & 0.980 \\
Without DDAB, $444 \mu \mathrm{g} \mathrm{l}^{-1}$ copper interferent & $0.032 \pm 0.019$ & $0.006 \pm 0.001$ & 0.991 \\
With DDAB, $444 \mu \mathrm{g} \mathrm{l}^{-1}$ copper interferent & $0.032 \pm 0.010$ & $0.006 \pm 0.001$ & 0.997 \\
\hline
\end{tabular}


established. The results obtained in the present study suggest that there is no role for surfactant vesicles, assuming they are formed, in the FI determination of arsenic with the apparatus used in this study. The only previous work involving FI appears to be that of Gutierrez et al. [9], who compared the use of several surfactants (cationic, anionic and neutral) in the determination of mercury (with borohydride reductant) by both FI and continuous flow (CF) procedures. For several anionic surfactants a decrease in sensitivity was obtained for FI and an increase for CF, for a cationic surfactant the FI signal was increased and the CF signal decreased, and the non-ionic surfactant had no effect on the FI sensitivity and caused a slight increase in the CF signal. The authors explained these results on the basis of the attraction of mercury cations to the surface of the anionic micelle, forming a microenvironment of enriched mercury concentration. When these ion-association complexes interacted with the borohydride, the rate of $\mathrm{Hg}(\mathrm{o})$ production was increased. The authors also suggested that there was "an improvement of the liquid phase transfer of the generated $\mathrm{Hg}(\mathrm{o})$ ". The negative effect in the FI mode was attributed to slow axial mixing between the injected sample (containing the mercury enriched micelles) and the acid carrier stream. This mechanism of enrichment on the surface of the micelle could also operate in the determination of arsenic (in aqueous solution as an anion) with the addition of a cationic surfactant (DDAB); it is possible that the benefits of this enrichment are offset by the proposed slow mixing between the micelles and the acid in the FI system so that the net effect is zero. However, in our experiments there was no acid concentration gradient between the sample zone and the acid carrier stream, as the samples contained the same concentration of acid as the carrier. Thus, the only on-line mixing of relevance is the radial mixing downstream from the confluence point, and thus our FI system is identical to a CF system in this regard.

It is also possible that the role of the surfactant is to enhance the wetting of surfaces involved in the processes of separating the generated hydride from the liquid phase and separating the bulk gas phase from the bulk liquid phase, thereby increasing their effectiveness. In our study, a quite different procedure was used to that of Aizpín Fernández et al. [3], who in turn used two different devices: a column device constructed in house for the AAS work, and a detuned grid nebulizer and associated spray chamber for the ICP-AES work. As the device used in our studies is known to be very efficient [15], it is possible that some of the enhancements reported by other workers are due to the process suggested by Gutierrez et al. [9], namely an enhanced gas-liquid separation.

We are currently investigating the possible role of surfactants in the FI generation of volatile species from the interaction of tetraethyl borate or borohydride with aqueous solutions of lead and cadmium [16]. We can confirm the determination of cadmium by a cold vapor procedure but, so far, no beneficial role for surfactants has been found.

\section{Acknowledgements}

The provision of equipment by the Perkin-Elmer Corporation is gratefully acknowledged.

\section{References}

[1] M.C. Valdés-Hevia y Temprano, B Aizpún Fernández, M. R. Fernández de la Campa and A. Sanz-Medel, Anal. Chim. Acta, 283 (1993) 175.

[2] M.C. Valdés-Hevia y Temprano, M.R. Fernández de la Campa and A. Sanz-Medel, J. Anal. Atom. Spectrom., 8 (1993) 821.

[3] B. Aizpún Fernández, M.C. Valdés-Hevia y Temprano, M.R. Fernández de la Campa, A. Sanz-Medel and P. Neil, Talanta, 39 (1992) 1517.

[4] M.C. Valdés-Hevia y Temprano, M.R. Fernández de la Campa and A. Sanz-Medel, J. Anal. Atom. Spectrom., 8 (1993) 847.

[5] A. Sanz-Medel, M.C. Valdés-Hevia y Temprano, N. Bordel Garcia and M.R. Fernández de la Campa, Anal. Proc. Inc. Anal. Commun., 32 (1995) 49.

[6] A. Sanz-Medel, M.C. Valdés-Hevia y Temprano, N. Bordel Garcia and M.R. Fernández de la Campa, Anal. Chem., 67 (1995) 2216.

[7] M.R. Fernández de la Campa, E. Sergivia Garcia, M.C. Valdés-Hevia y Temprano, B. Aizpún Fernández, J.M. Marchante Gayon and A. Sanz-Medel, Spectrochim. Acta Part B, 50 (1995) 377.

[8] B. Aizpún Fernández, M.R. Fernández de la Campa and A. Sanz-Medel, J. Anal. Atom. Spectrom., 8 (1993) 1097.

[9] J.M. Gutierrez, Y. Madrid and C. Càmara, Spectrochim. Acta Part B, 48 (1993) 1551.

[10] Y. Madrid, J.M. Gutierrez and C. Camara, Spectrochim. Acta Part B, 49 (1994) 163.

[11] L.J. Cline-Love, J.G. Habarta and J.G. Dorsey, Anal. Chem., 56 (1984) 1132A. 
[12] J. Mora, A. Canals and V. Hernandis, J. Anal. Atom. Spectrom., 6 (1991) 139.

[13] J. Dedina and D.L. Tsalev, Hydride Generation Atomic Absorption Spectrometry, Wiley, New York, 1995, pp. 182245.
[14] S.J. Hill, J.B. Dawson, W.J. Price, I.L. Shuttler and J.F. Tyson, J. Anal. At. Spectrom., 10 (1995) 199R.

[15] C.P. Hanna, P.E. Haigh, J.F. Tyson and S. McIntosh, J. Anal. Atom. Spectrom., 8 (1993) 585.

[16] S. Kradtap and J.F. Tyson, Anal. Commun., in preparation. 